\title{
Effect of Topical Steroids on Skin Prick Test: A Randomized Controlled Trial
}

\author{
Anne R. Ebbesen (D) - Lene A. Riis · Josefine Gradman
}

Received: March 23, 2018 / Published online: May 4, 2018

(C) The Author(s) 2018

\begin{abstract}
Introduction: Topically applied corticosteroids on the skin can significantly inhibit the wheal response to allergens in skin prick test (SPT). The duration of this effect is unknown. The aim of this study is to investigate the duration of the inhibitory effect of topical corticosteroids on SPT.
\end{abstract}

Methods: Twenty-two healthy subjects were included in a single-blinded randomized study. All subjects were skin prick tested using a standard inhalant allergen panel. The subjects were randomized to treat either the left or right forearm with Betnovat ${ }^{\circledR}$ cream (group III steroid) once a day for 10 days. Subsequently, the subjects were skin prick tested the following 5 days and at day 8 on both forearms.

Results: At baseline, the 22 individuals had positive SPT for a total of 72 allergens. Compared with the untreated arm, the mean size of the wheals was significantly reduced on day 1 (12 $\mathrm{h}$ after end of treatment) by $0.56 \mathrm{~mm}(95 \%$ confidence interval (CI) $[0.06 ; 1.06], p=0.03$ ) for allergens and $0.70 \mathrm{~mm} \quad[0.32 ; 1.09]$

Enhanced Digital Features To view enhanced digital features for this article go to https://doi.org/10.6084/ m9.figshare.6160256.

A. R. Ebbesen $(\square) \cdot$ L. A. Riis · J. Gradman Department of Pediatrics, Regional Hospital Central Jutland, Viborg, Denmark

e-mail: ebbesen.anne@gmail.com $(p=0.001)$ for histamine. On day 2 (36 h after end of treatment), the mean difference between treated and untreated arm was $0.47 \mathrm{~mm}[-0.08$; 0.85 ] $(p=0.02)$ for allergen-induced wheals and $0.22 \mathrm{~mm}[-0.21 ; 0.64](p=0.31)$ for histamineinduced wheal. On day $3,4,5$, and 8 , there was no significant difference.

Conclusions: Treatment with topical steroid significantly inhibited the response to SPT for $36 \mathrm{~h}$ but for less than 3 days. In addition, we demonstrated that topical applied corticosteroids inhibit the mean wheal size of the positive histamine control for a shorter time than for the allergens. Consequently, positive response to histamine control is not a valid marker for reliable skin prick test in steroidtreated patients.

Plain Language Summary: Plain language summary available for this article.

Keywords: Betnovat; Corticosteroids; Skin prick test; SPT; Steroids

\section{PLAIN LANGUAGE SUMMARY}

Atopic dermatitis is the most common skin disease in childhood. It is associated with sensitization to allergens, and children with atopic dermatitis have increased risk of developing allergic rhinitis and asthma.

Skin prick test (SPT) is a safe and efficient way to investigate whether a patient is 
sensitized to allergens. The procedure is minimally invasive and can be used in all ages.

A variety of factors can affect SPT, with the potential to alter test outcomes. Previous studies have shown that topical dermal corticosteroids inhibit the wheal and flare response in SPT. However, the duration of such inhibition is unknown.

Topically applied corticosteroids are widely used for atopic dermatitis. Before skin testing of patients treated with topical steroids, it is important to know for how long the medicine should be withheld to achieve a reliable result, but at the same time without an unnecessarily long medicine pause.

In this study we included 22 healthy subjects. The subjects were randomly assigned to treatment of either the left or right forearm with Betnovat ${ }^{\circledR}$ cream (corticosteroid) once a day for 10 days. Subsequently, the subjects were skin prick tested the following 5 days and at day 8 on both forearms to compare if there were any difference in the wheal response.

We showed that treatment with topical steroid inhibited the response to a SPT for at least $36 \mathrm{~h}$. Therefore, only 3 days of withdrawal of topical steroids is necessary to obtain a reliable result in skin prick test.

\section{INTRODUCTION}

Skin prick test (SPT) was introduced in 1865 by Blackly [1] and is still one of the most widely used screening and diagnostic tools in allergy practice [2].

In sensitized patients, mast cells have specific IgE antibodies attached on their surfaces. Introduction of an allergen into the skin triggers activation of local mast cells that release mediators responsible for the immediate wheal and flare reaction (type 1 reaction).

The SPT is a safe and efficient way to investigate if a patient is sensitized to allergens [2]. It is easy to perform, with results available within $15-20 \mathrm{~min}$. It is cost-effective and allows for evaluation of multiple allergens in a single session [2]. The procedure is minimally invasive and can be used in all ages.
Atopic dermatitis is the most common skin disease in childhood, and it is associated with sensitization to allergens. Furthermore, children with atopic dermatitis are predisposed to develop allergic rhinitis and asthma [3].

A variety of factors such as antihistamines and systemic corticosteroids can affect SPT and significantly alter test outcomes $[4,5,8,10,11,12,14]$. Also, topical dermal corticosteroids inhibit the wheal and flare response to histamine and allergens $[4,5,8,9]$. However, the duration of the inhibitory effect has not been investigated.

It is important to know for how long treatment with topical corticosteroid should be withheld in patients with atopic dermatitis. This knowledge will ensure reliable results without unnecessary medicine discontinuation. International guidelines suggest 1-3 weeks abstinence of topical steroids in the testing area, depending on dosage and length of treatment [6].

The aim of this study is to investigate for how long the effect of topically applied corticosteroids inhibits the wheal reaction in a SPT. We used betamethasone-17-valerate cream $0.1 \%$ (Betnovat $^{\circledR}$ ), a moderate class III topical steroid [7].

\section{METHODS}

Twenty-two healthy subjects were included in the study, 20 women and 2 men, aged 18-70 years (mean age 41 years). To be included the subjects had to be sensitized to at least one inhalant allergen.

Exclusion criteria were: atopic eczema or other skin disease, skin infection or open wounds on the forearm, a positive reaction to the negative control, pregnant and lactating females, subjects with known hypersensitivity to the ingredients of Betnovat ${ }^{\circledR}$, any use of the following drugs prior to or during the study period: systemic or topic corticosteroids (4 weeks), topical tacrolimus (14 days), topical pimecrolimus (7 days), antihistamines (7 days), allergen immunotherapy, tricyclic antidepressants ( 4 weeks), and beta-blockers. 
SPT was performed using the standard panel ALK Soluprick ${ }^{\circledR}$ SQ consisting of 10 inhalant allergen extracts, a positive control (histamine dihydrochloride $10 \mathrm{mg} / \mathrm{ml}$ ), and a negative control (saline). Tested allergens were birch, timothy grass, mugwort, horse, dog, cat, house dust mites (Dermatophagoides pteronyssinus and Dermatophagoides farinae), and molds (Alternaria and Cladosporium).

SPT was performed on the volar surface of both forearms in accordance with international guidelines [6]. A 1-mm precision lancet (ALK) was passed through the drop and inserted into the epidermal surface. The solution was then gently removed with paper tissue. The SPT readings were performed after $15 \mathrm{~min}$. The outlines of the induced wheal were marked with a pen and transferred by tape to graph paper. The size of the wheal was measured using a millimeter rule. The size of each wheal was measured as $(D+d) / 2$, where $D$ is the largest diameter and $d$ is the perpendicular diameter at the midpoint of $D$. A test was considered positive if the wheal diameter was $\geq 3 \mathrm{~mm}$ [6].

The subjects were randomized to apply Betnovat ${ }^{\circledR}$ cream to either the volar side of the left or right forearm once a day $(10 \mathrm{pm} \pm 1 \mathrm{~h})$ for 10 consecutive days. The randomization was performed by a doctor using sealed envelopes containing two identical notes saying: "apply Betnovat cream to your left arm" or "apply Betnovat cream to your right arm." The subjects kept one of the notes, while the other note stayed in the envelope at the site. The subjects received a $30 \mathrm{~g}$ tube of Betnovat ${ }^{\circledR}$ cream at the site. The steroid tubes were weighed before they were handed out and again when they were returned. The subjects were instructed to apply the cream as a thin film on the volar forearm using one finger tip unit per day. The subjects also received a diary to mark if they had remembered to apply the cream as instructed. If a subject had applied the cream for fewer than 7 days, they were excluded from the study.

After 10 days of applying the topical steroid, the subjects were skin prick tested for five consecutive days and at day 8 at $10 \mathrm{am} \pm 1 \mathrm{~h}$. Day 1 corresponded to $12 \mathrm{~h}$, day 2 corresponded to $36 \mathrm{~h}$, and day 3 corresponded to $60 \mathrm{~h}$ after applying the cream. SPT was performed on both volar forearms using the previous positive allergens as well as histamine and saline control.

Skin prick tests were performed by a study nurse who was blinded to the randomization, i.e., to which arm the topical steroid had been applied.

All procedures performed were in accordance with ethical standards of the institutional research committee and with the Helsinki Declarations. Informed consent was obtained from all individual participants included in the study.

\section{Statistical Analysis}

Data analyses were performed using STATA version 13 (StataCorp, College Station, TX 77845). The size of the wheals was compared using Student's paired $t$ test. $p<0.05$ was considered statistically significant. The sample size of 20 subjects was based on the ability to detect a $1.0 \mathrm{~mm}$ reduction in wheal size between the treated and untreated arm with power of $80 \%$, alpha error of $5 \%$, and estimated standard deviation of $0.5 \mathrm{~mm}$. To allow for $10 \%$ dropout, we included 22 subjects in the study.

\section{RESULTS}

All 22 subjects completed the study. No reported adverse events were considered to be drug or procedure related. At baseline, the 22 individuals had positive SPT to a total of 72 allergens.

Table 1 Positive skin prick test results for the 22 included participants

\begin{tabular}{|c|c|c|c|c|c|c|c|c|c|c|}
\hline \multicolumn{10}{|c|}{$N=22$} & \multirow[t]{2}{*}{ Total } \\
\hline Birch & Grass & Mugwort & Horse & Dog & Cat & D. pteronyssinus & D. farinae & Alternaria & Cladosporium & \\
\hline 18 & 15 & 7 & 0 & 4 & 9 & 10 & 9 & 0 & 0 & 72 \\
\hline
\end{tabular}




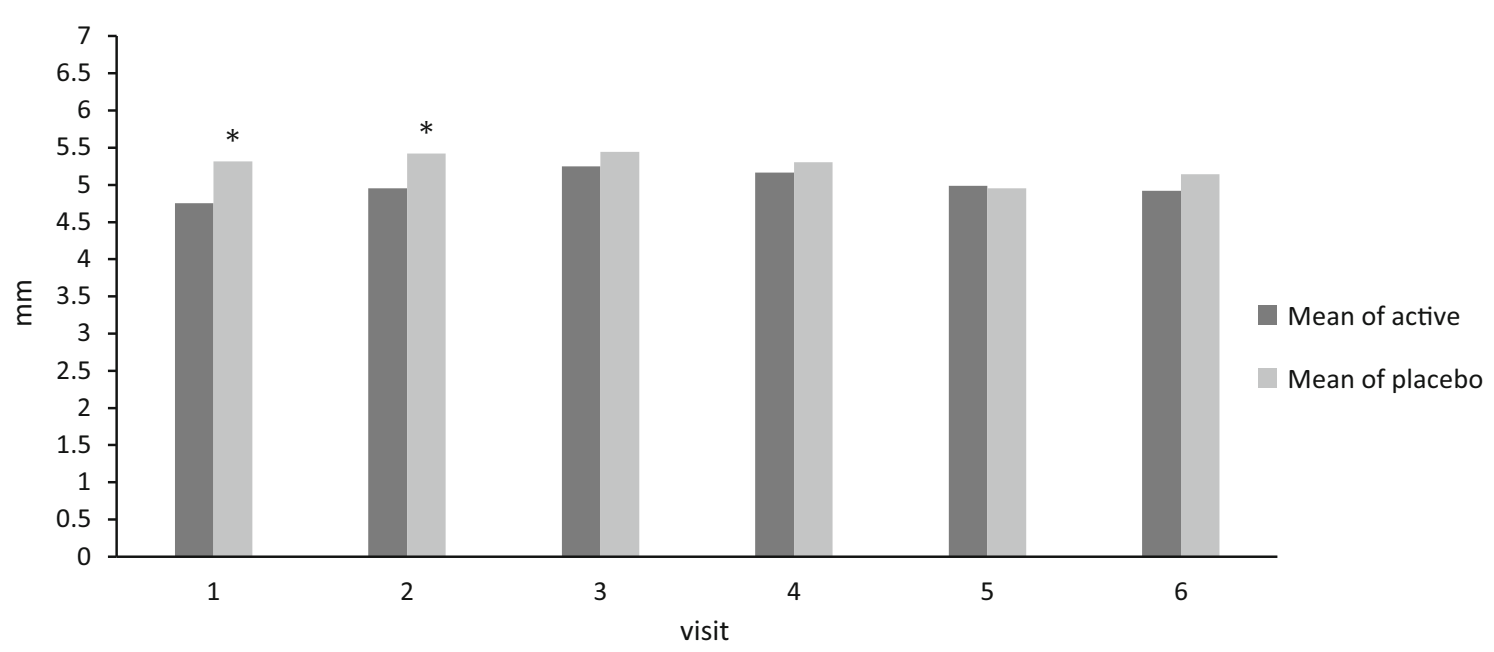

Fig. 1 Mean size of allergen-induced wheals. ${ }^{*} p<0.05$

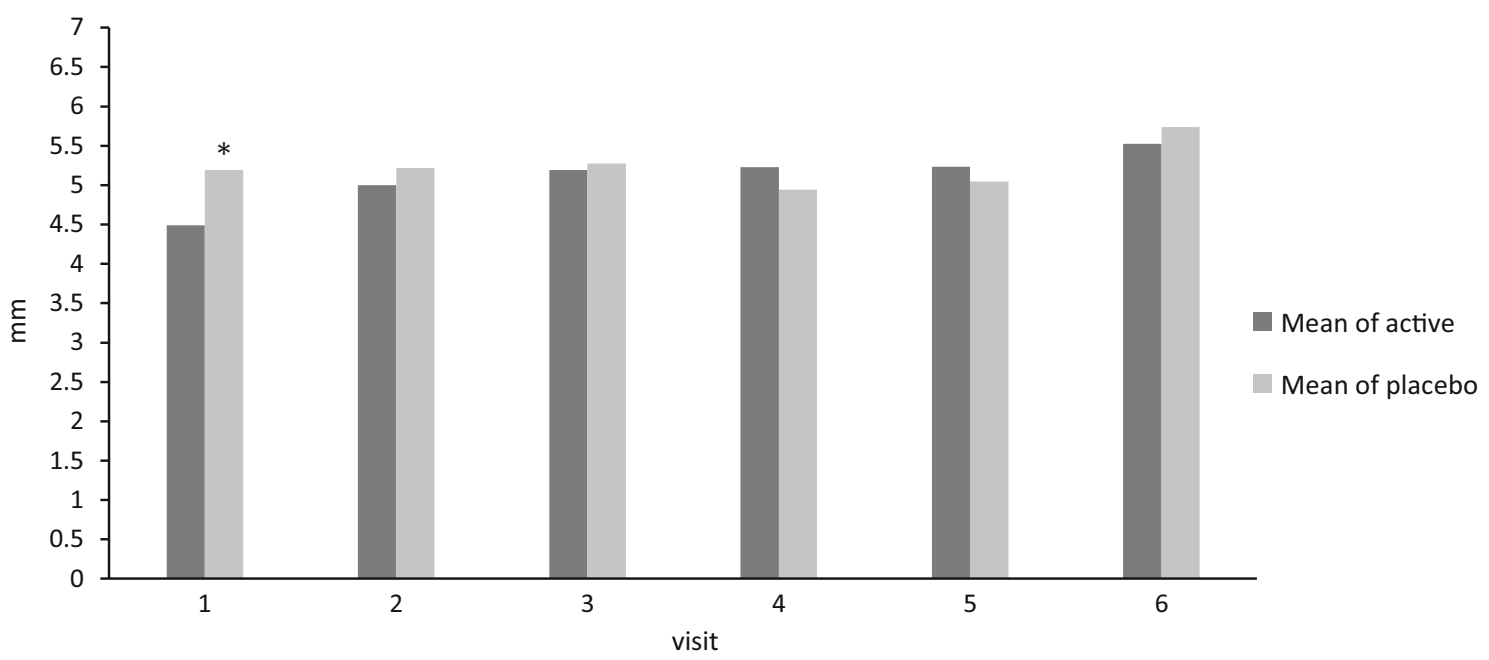

Fig. 2 Mean size of histamine-induced wheals. ${ }^{*} p<0.05$

The subjects were sensitized to one to five allergens. Birch and grass pollen were the most common positive reactions (Table 1).

The median (quartiles) amount of cream used was $4.31 \mathrm{~g}(2.94 ; 6.38)$.

The wheal reactions are presented in Figs. 1 and 2. Compared with the untreated arm, applying steroid for 10 days resulted in significantly reduction of the mean size of the allergen- and histamine-induced wheals at day 1 (12 $\mathrm{h}$ after ended treatment). The mean reduction of the allergen wheals was $0.56 \mathrm{~mm} \mathrm{95 \%} \mathrm{CI}$
$[0.06 ; 1.06](p=0.03)$ and for histamine was $0.70 \mathrm{~mm}[0.32 ; 1.09](p=0.001)$.

At day 2 ( $36 \mathrm{~h}$ after ended treatment), the response to allergen was significantly suppressed, but not that to histamine. The mean difference between the steroid-treated and untreated arm was $0.47 \mathrm{~mm}[-0.08 ; 0.85]$, $(p=0.02)$ for allergens and $0.22 \mathrm{~mm}[-0.21$; $0.64](p=0.31)$ for histamine. From day 3 , there was no significant difference between the mean size of the wheals on the two arms. There was no difference in the response to the various allergens. 


\section{DISCUSSION}

To the best of the authors' knowledge, this is the first study to demonstrate for how long dermally applied corticosteroids inhibit allergen-induced wheals in SPT. This information is important to obtain reliable SPT results while avoiding unnecessary medicine discontinuation. In the case of mild to moderate potent steroids, this study indicates that only 3 days of abstinence is sufficient to obtain a reliable SPT result.

Topical steroids result in a reduction of both the number and histamine content of mast cells in the skin [5]. It is common practice to use a histamine control to examine whether SPT can be performed if a patient has used any medication that may interfere with the SPT. Furthermore, this study showed that, in case of topical steroids, the histamine control seems to be suppressed for a shorter time period than the allergen extracts, which could easily lead to false-negative skin prick test results. Similar results have been found in previous studies with topical steroids $[5,6]$. This is due to the different mechanisms: while the allergen response is dependent on activation of mast cells, the positive histamine control acts independently of mast cells.

The size of the wheals on the untreated arm did not change significantly over time, indicating that we observed no systemic effect of steroid treatment on the SPT.

Based on the diaries, adherence to the protocol was excellent. The subjects were instructed to apply one fingertip unit, i.e., approximately $0.5 \mathrm{~g}$, of Betnovat ${ }^{\circledR}$ cream once daily for 10 days. The median amount used was slightly less than expected (4.3 g), but with remarkably large variation. This probably illustrates the difficulty in instructing patients to use a standardized amount of cream. We cannot exclude that a larger amount of cream would have resulted in longer suppression of the wheal response. However, 10 consecutive days of applying steroid cream is probably sufficient to explore the effect of topical steroids on the responsiveness of the skin. Off-protocol analyses revealed no difference in wheal response for those 11 subjects who had used the greatest amount of steroid cream compared with those who had used the smallest amount of steroid cream.

Atopic dermatitis is primarily a disease of childhood. For ethical reasons we conducted this study in adults, as most children (and adults) consider the skin prick test slightly painful and the subjects in this study agreed to have a total of 14 skin prick tests performed. The reactivity of the skin may vary with age [13]. In the present study, the size of the wheals was compared with each subject's own untreated arm, making the potential influence of age low. The study was performed singleblinded. We do not believe that the fact that the subjects were not blinded influenced the size of the wheals.

The study was performed in healthy individuals. It is likely that patients with atopic dermatitis will have increased absorption of applied steroids due to a defective skin barrier. This is the reason why we chose to apply a potent steroid for as long as 10 days. However, it is possible that the study underestimates the suppressive effect in patients with severe atopic dermatitis.

\section{CONCLUSIONS}

We showed that treatment with topical highpotency steroid significantly inhibited the response to SPT for $36 \mathrm{~h}$ but less than 3 days. The observed reduction of wheal size of $0.56 \mathrm{~mm}[0.06 ; 1.06]$ may in many cases be clinically relevant. Based on these data, we recommend pausing topical steroid treatment on the volar side of the forearm for $72 \mathrm{~h}$ before skin testing. The duration of abstinence should be longer in case of more potent topical steroids. In addition, it is important to note that a positive response to a histamine control is not necessarily a valid marker for a reliable SPT.

\section{ACKNOWLEDGEMENTS}

Special thanks go to the study participants for their involvement in this study. 
Funding. Sponsorship for this study and article processing charges were funded by a research grant from the Regional Hospital Central Jutland. The sponsor had no financial interest.

Authorship. All named authors meet the international Committee of Medical Journal Editors (ICMJE) criteria for authorship for this article, take responsibility for the integrity of the work as a whole, and have given their approval for this version to be published.

Disclosures. Ebbesen AR, Riis LA and Gradman $\mathrm{J}$ have nothing to disclose.

Compliance with Ethics Guidelines. All procedures performed were in accordance with ethical standards of the institutional research committee and with the 1964 Helsinki Declarations and its later amendments or comparable ethical standards. Informed consent was obtained from all individual participants included in the study.

Data Availability. The datasets generated and analyzed during the current study are available from corresponding author on reasonable request.

Open Access. This article is distributed under the terms of the Creative Commons Attribution-NonCommercial 4.0 International License (http://creativecommons.org/licenses/ by-nc/4.0/), which permits any noncommercial use, distribution, and reproduction in any medium, provided you give appropriate credit to the original author(s) and the source, provide a link to the Creative Commons license, and indicate if changes were made.

\section{REFERENCES}

1. Blackley $\mathrm{CH}$. Hay fever: its causes, treatment, and effective prevention; experimental researches. 2nd ed. London: Bailliere, Tindall and Cox; 1880.

2. Bousquet J, Heinzerling L, Bachert C, Papadopoulos NG, Bousquet PJ, Burney PG, et al. Practical guide to skin prick tests in allergy to aeroallergens. Allergy. 2012;67(1):18-24.

3. Grabenhenrich LB, Keil T, Reich A, Gough $\mathrm{H}$, Beschorner J, Hoffmann U, Bauer CP. Prediction and prevention of allergic rhinitis: a birth cohort study of 20 years. J Allergy Clin Immunol. 2015;136(4):932-40.

4. Pipkorn U, Hammarlund A, Enerbäck L. Prolonged treatment with topical glucocorticoids results in an inhibition of the allergen-induced wheal-and-flare response and a reduction in skin mast cell numbers and histamine content. Clin Exp All. 1989;19(1):19-25.

5. Andersson M, Pipkorn U. Inhibition of the dermal immediate allergic reaction through prolonged treatment with topical glucocorticosteroids. J Allergy Clin Immunol. 1987;79(2):345-9.

6. Heinzerling L, Mari A, Bergmann KC, Bresciani M, Burbach G, Darsow U. The skin prick test-European standards. Clin Transl Allergy. 2013;3(1):3.

7. WHO's Classification of Topical Corticosteroids. http://apps.who.int/medicinedocs/en/d/Jh2918e/ 32.html. Accessed 6 Dec 2017.

8. Shah KM, Rank MA, Dave SA, Oslie CL, Butterfield JH. Predicting which medication classes interfere with allergy skin testing. Allergy Asthma Proc. 2010;31(6):477-82.

9. Narasimha SK, Srinivas CR, Mathew AC. Effect of topical corticosteroid application frequency and histamine induced wheals. Int $\mathrm{J}$ Dermatol. 2005;44(5):425-7.

10. Gradman J, Wolthers OD. Suppressive effects of topical mometasone furoate and tacrolimus on skin prick testing in children. Pediatr Dermatol. 2008;25(2):269-70.

11. Spergel JM, Taylor P, Parneix Spake A. Effect of topical pimecrolimus on epicutaneous skin testing. J Allergy Clin Immunol. 2004;114(3):695-7.

12. Canonica GW, Bousquet J, Casale T, Lockey RF, Baena-Cagnani CE, Pawankar R. Sub-lingual immunotherapy: World Allergy Organization Position Paper 2009. Allergy. 2009;64(Suppl 91):1-59.

13. Skassa-Brociek W, Manderscheid JC, Michel FB, Bousquet J. Skin test reactivity to histamine from infancy to old age. J Allergy Clin Immunol. 1987;80(5):711-6.

14. Pearlman DS, Grossman J, Meltzer EO. Histamine skin test reactivity following single and multiple doses of azelastine nasal spray in patients with seasonal allergic rhinitis. Ann Allergy Asthma Immunol. 2003;91(3):528-62. 